\title{
Accelerating the Formation of the New Development Pattern in Northern Anhui with Higher Quality Development of Digital Economy
}

\author{
Hao Xing, Zhian Ren, Qin Tang \\ School of Economics, Anhui University of Finance and Economics, Bengbu, China \\ Email: Renzhianyang1@163.com
}

How to cite this paper: Xing, H., Ren, Z. A., \& Tang, Q. (2020). Accelerating the Formation of the New Development Pattern in Northern Anhui with Higher Quality Development of Digital Economy. Modern Economy, 11, 2041-2054.

https://doi.org/10.4236/me.2020.1112136

Received: November 5, 2020

Accepted: December 26, 2020

Published: December 29, 2020

Copyright () 2020 by author(s) and Scientific Research Publishing Inc. This work is licensed under the Creative Commons Attribution International License (CC BY 4.0).

http://creativecommons.org/licenses/by/4.0/

\begin{abstract}
Promoting the higher quality development of digital economy through power change, efficiency change, quality change and scale change is conducive to breaking through the cycle blocking point of new development pattern, improving cycle efficiency, improving cycle quality and reducing cycle cost. To form the new development pattern in Northern Anhui, there are some problems, such as insufficient innovation ability, insufficient coordination and sharing, weak green growth, low degree of openness and few leading enterprises. In order to accelerate the formation of the new development pattern in Northern Anhui with higher quality development of digital economy, we can follow the basic path of " 1235 ", that is, focusing on the " 1 " center of modern economic system construction, grasping the "2" main lines of digital industry priority development and supply side structural reform, and strengthening the " 3 " strategies of innovation driven strategy, "double leader" strategy and Rural Revitalization Strategy Lead ,and realizing the " 5 " aspects accelerated development of digital talent reserve, digital finance, high-level opening to the "outside", industrial chain and value chain upgrade and regional mutual benefit and sharing.
\end{abstract}

\section{Keywords}

Digital Economy, High Quality Development, New Development Pattern

\section{Introduction}

Accelerating the formation of a new development pattern in which the domestic 
cycle is the main body and the domestic and international dual cycles promote each other is a strategic decision made in accordance with China's development stage, environment, and changes in conditions. It is a systematic and deep-level change that concerns the overall situation. Northern Anhui, as a relatively backward area in Anhui Province, should seize the opportunity of this major development strategy transformation, quickly reverse the inherent development trend, firmly grasp the strategic basis of the new development pattern, seek new growth points, and strive to expand development space, forming a new development pattern as soon as possible in the whole province and even the whole country, and promote higher quality development in northern Anhui. However, the development of northern Anhui has its particularities, and there are many long-term unresolved constraints. How should such underdeveloped regions build a new development pattern? Had to urge people to think and trigger inquiry. Today, with the rapid development of the digital economy, new products, new services, new formats, and new business models supported by digital technology have become the main contributors to economic growth. Therefore, the digital economy should become the most important driving force in the construction of a new development pattern with the domestic cycle as the main body and the domestic and international double cycles mutually promoting each other (Jiang, 2020; Qian \& Pei, 2020; Liu, 2020). However, there is a problem here that requires us to have a clear understanding. Does Northern Anhui have a basis for the development of a digital economy? Can the digital economy be developed well? The answer is yes. Not only that, but more importantly, we must always firmly believe in this. Even if the current conditions are not very mature, we must make great efforts to create conditions for the development of the digital economy in the future. If you hesitate and slow down, you can say unceremoniously that the northern Anhui region will lose another opportunity to accelerate development, and it is still unknown when the revitalization of northern Anhui will actually come. To this end, we must establish strong beliefs, reform and innovate, and forge ahead, take the higher-quality development of the digital economy as the starting point, accelerate and form a new development pattern as soon as possible, promote higher-quality development in northern Anhui, and realize the revitalization of northern Anhui.

The article structure of this paper mainly includes four aspects, specifically as follows: firstly, it studies the theoretical mechanism of higher quality development of digital economy to promote the formation of the new development pattern; secondly, it analyzes the main problems in the construction of the new development pattern in Northern Anhui; thirdly, it sorts out the significant advantages of higher quality development of digital economy in Northern Anhui; finally, it obtains the following conclusions that it is feasible to use higher quality development of digital economy to accelerate the formation of the new development pattern in Northern Anhui Province, and on this basis, the specific implementation path is proposed. 


\section{Theoretical Mechanism}

To build a new development pattern, we must pay attention to the development of the new economy. As General Secretary Xi Jinping pointed out, "the new normal requires new momentum, and the digital economy can do a lot in this regard". The digital economy is an important representative of the new economy. Its higher quality development is conducive to the efficient and smooth flow of all links from production, distribution, circulation and consumption. The smooth flow of all links is also the key to the "big cycle" and "double cycle" (Xu, 2020). The higher-quality development of the digital economy is to promote the digital economy to achieve scale changes through the development of industrial integration on the basis of realizing the power change, efficiency change and quality change of the digital economy itself (Figure 1).

\subsection{Through the Innovation Drive, Accelerate the Digital Economy to Realize the Power Change, and Break through the Circulation Blocking Point of the New Development Pattern}

The new development pattern points out that it is necessary to take the domestic big cycle as the main body to form a situation where the domestic and international double cycles promote each other. This requires first to solve the problems and difficulties of the "big cycle" and the The "stuck neck" technology will not be cut off due to foreign blockades (Huang, 2020a; Lv \& Li, 2020). As the main representative of the new economy, the digital economy is inherently innovative, but under the construction of a new development pattern, its focus needs to focus on the main contradictions, and through higher-level innovation activities, to accelerate the digital economy to achieve power change. First, gather major companies and talents for the development of the digital economy through institutional

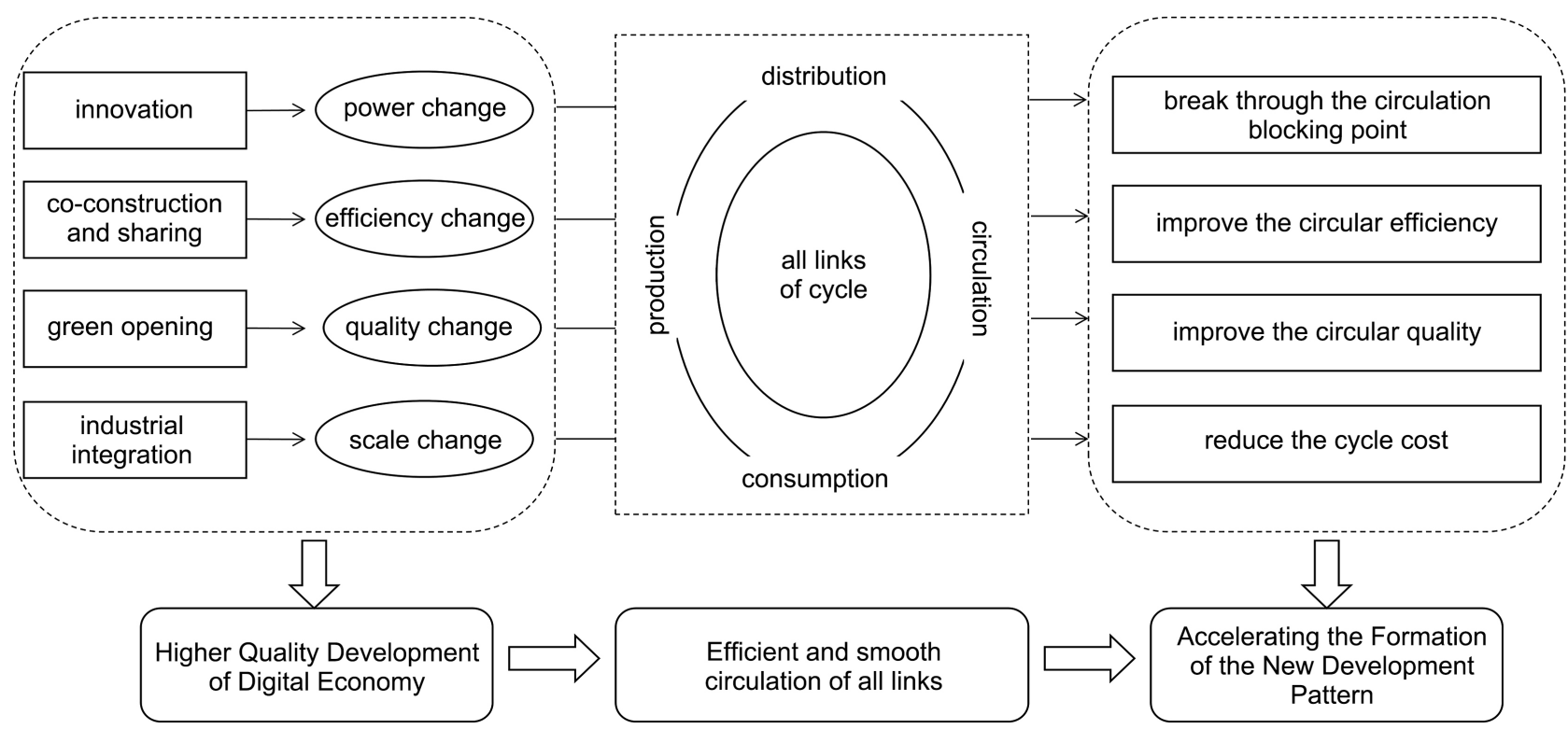

Figure 1. The theoretical mechanism of higher quality development of digital economy to promote the formation of the new development pattern. Source: Created by the author. 
innovation $(\mathrm{Li}, 2020)$ that refers to the innovation of realizing the sustainable development and reform of the society by creating new and more effective systems and norms to stimulate people's behavior under the conditions of people's existing production and living environment; secondly, integrate the capital source channels for the development of the digital economy through financial innovation (Fan \& Xu, 2020). Financial innovation is to change the existing financial system and add new financial instruments in order to obtain the potential profits that cannot be obtained by the existing financial system and financial instruments, finally, gather major forces to concentrate on conquering core technologies through technological innovation. Scientific and technological innovation is the general term of original scientific research and technological innovation. It refers to the process of creating and applying new knowledge, new technology and new craftwork, adopting new production mode and management mode, developing new products, improving product quality and providing new services. Make up for the shortcomings of the scientific and technological research and development industry chain (Lu, 2020). Drive the digital economy through innovation to accelerate the realization of the power changes, promote the digital economy to achieve higher-quality development, solve the breakpoints, difficulties and blockages faced by the new development pattern, and provide conditions for subsequent improvement of cycle efficiency, improvement of cycle quality, and reduction of cycle costs.

\subsection{Through Co-Construction and Sharing, We Will Promote the Digital Economy to Realize Efficiency Changes and Improve the Circular Efficiency of the New Development Pattern}

Efficiency is one of the key issues that need to be resolved under the new development pattern. Only high-efficiency cycles can truly promote high-quality economic development, and it is also conducive to the rapid formation of a new development pattern. After entering the era of the Internet of Everything, the production of data is growing at an exponential rate. Data has become one of the key elements to promote economic growth and has become the core asset of many companies (Shi \& Shan, 2020). Although the digital economy is developing rapidly, there are also problems such as the monopoly of data resources by leading enterprises, the low level of equalization of the digital foundation, and the slow progress of digital technology applications in some areas. These problems cannot be effectively solved and will inevitably hinder the development efficiency of digital economy. Co-construction and sharing is one of the key means to solve the above problems. One is to build a hierarchical management mechanism for data resources. According to the source, nature, and confidentiality of the data, the data is divided into different levels from private to public for subsequent co-construction and sharing provides basic support. The second is to guide the formation of a co-construction and sharing mechanism within the region and between regions, and between industries and industries. According to the data level, combining the different requirements of regions, industries, and 
departments, establish a co-construction mechanism and orderly data resources The open sharing mechanism promotes the digital economy to achieve efficiency changes. Promote the circular efficiency improvement of the new development pattern through the efficiency reform of the digital economy.

\subsection{Through Green Opening, We Will Help the Digital Economy to Achieve Quality Changes and Improve the Circular Quality of the New Development Pattern}

Low-quality and closed economic development has only gained backwardness and passivity. The actual experience of China's reform and opening up fully illustrates the importance of open development, but ignoring green development can also cause some economic development problems. Therefore, only by adhering to green and open development can the quantity and quality of economic development be improved. The same is true for the development of the digital economy. It is necessary to strengthen the construction of top-level design, laws and regulations and industry standards to guide the open development of the digital industry (Li et al., 2020), avoid the formation of a passive situation of "A hundred schools of thought contend". Promote the digital economy to achieve quality changes and make the digital economy truly a powerful representative of green and open development. The cycle quality under the new development pattern is not a simple repetition of production, distribution, circulation and consumption, but a spiral and continuous improvement process, which requires continuous improvement of the quality of the supply side and the demand side. Helping the digital economy to achieve quality changes through green opening and improving the higher-quality development of the digital economy is conducive to improving the open level of digital elements, realizing the quality of market-oriented configuration of digital elements, and enabling the digital economy to participate in the various links of production, distribution, circulation and consumption with higher quality. It is conducive to promoting and improving the cycle quality of the new development pattern.

\subsection{Promote the Digital Economy to Achieve Scale Change through Industrial Integration and Reduce the Cycle Cost of the New Development Pattern}

The development of the digital economy is not only its own development, but also through its direct integration with other industries to promote the development of industrial digitalization and digital industrialization. Only by integrating the digital economy with industrial development can the scale development of the digital economy be realized and the "magnification effect" and "reduction effect" of the digital economy can be maximized. Among them, the "magnification effect" is mainly reflected in increasing the online income of offline industries and increasing the scale income after digital industrialization; in the "reduction effect", it is mainly reflected in the digital economy's ability to reduce the cost of each link of industrial development, such as procurement, production, trans- 
portation, management, and human resources, and will reduce information cost, transaction cost and management cost after digital industrialization. To build a new development pattern, it is not only necessary to solve blockages, breakpoints and difficulties, and to improve cycle efficiency and cycle quality, but also need to focus on reducing cycle costs. If we blindly pursue the "dual cycle" without considering the cost factor, even if the new development pattern is first constructed, it will be of low quality and violate the original intention of the country to put forward the new development pattern theory. Therefore, promoting the scale development of the digital economy through industrial integration and development, and ultimately reducing the cycle cost of the new development pattern, is also an important part of building a new development pattern.

\section{Main Problems}

If the northern Anhui region wants to be in the forefront of constructing the new development pattern, it must pay attention to the practical problems currently faced in constructing a new development pattern. In general, the northern Anhui region faces the following five main problems.

\subsection{The Innovation Ability Is Not Strong, Which Increases the Resistance to Break through the Difficulties in the New Development Pattern}

Innovation ability is the key ability to break through the barriers and difficulties in the new development pattern. However, according to the "Anhui Provincial Science and technology statistical bulletin in 2019", it can be seen that compared with other regions in the province, Northern Anhui has obvious disadvantages in terms of innovative talent reserve, $\mathrm{R} \& \mathrm{D}$ platform construction, high-tech enterprises, R \& D investment intensity and scientific and technological output. Compared with other developed regions in China, the gap is larger, and the innovation ability still needs to be strengthened. It also increases the resistance to break through the new development pattern. For example, in the construction of $\mathrm{R} \& \mathrm{D}$ platforms, there were $631 \mathrm{R} \& \mathrm{D}$ platforms at the provincial level and above in northern Anhui in 2018, accounting for only $23.88 \%$ of the province, which is lower than $44.52 \%$ in central Anhui and $31.6 \%$ in southern Anhui ${ }^{1}$.

\subsection{The Lack of Coordination and Sharing Is Not Conducive to the Rapid Improvement of the Cycle Efficiency of the New Development Pattern}

Coordination and sharing is one of the main means to improve the circulation efficiency of the new development pattern. The industrial structure of primary, secondary, and tertiary industries in northern Anhui has changed from 0.21:0.45:0.34 in 2009 to 0.14:0.43:0.43 in 2018 (Ren \& Xing, 2020). Although

${ }^{1}$ Northern Anhui includes Bengbu, Fuyang, Suzhou, Bozhou, Huaibei and Huainan; Central Anhui includes Hefei, Chuzhou, Lu'an and Anqing; Southern Anhui includes Wuhu, Maanshan, Tongling, Xuancheng, Chizhou and Huangshan. 
there has been improvement, compared with developed regions, there are still relatively big gap. In terms of the coordinated development of urban and rural areas, there are still some unreasonable phenomena in the efficiency of income distribution, fair distribution, and rural revitalization, which need to be further improved. For example, the income ratio of urban and rural residents in northern Anhui was 2.58 in 2009 and it was 2.8 in 2013, and it was 2.47 in 2017. Although it has improved, the effect is not significant, and there is a trend of further expansion during the period.

\subsection{Weak Green Growth Has Increased the Pressure on the Cycle Quality of the New Development Pattern}

To ensure the circular quality of the new development pattern, more attention must be paid to green development. With the introduction of new development concepts and the reform of the coal resource tax, the profit margins of coal companies have been severely compressed, and some have even suffered losses. The government and companies are unable to support the high transformation costs; Similarly, similar to coal companies, because the industrial development in northern Anhui is mostly at the middle and low end of the industrial chain and value chain, and it has undertaken many industrial transfer tasks in the Yangtze River Delta, such as chemical industry, rubber, leather, and textile, these industries generally have strong pollution, under the high-pressure line of environmental protection, the pressure to achieve green development is still great.

\subsection{The Degree of Openness Is Not High, Which Is Not Convenient for the Efficient Improvement of the Cycle Quality of the New Development Pattern}

The degree of openness is one of the important factors to improve the circular quality of the new development pattern. Opening up and reform are often inseparable. Reform is promoted through opening up (Bi et al., 2019), and quality is improved through reform. A greater degree of openness is the basis for promoting the "double cycle". However, the level of openness in northern Anhui is not too high, such as the number of foreign-invested enterprises. In 2018, there were 1240 foreign-invested enterprises in northern Anhui, accounting for only $18.76 \%$ of the province's total, which is less than half of Hefei. Compared with southern Anhui, there are more than 700 fewer $^{2}$.

\subsection{There Are Not Many Leading Companies, Which Is Not Conducive to the Effective Reduction of the Cycle Cost of the New Development Pattern}

Leading companies are particularly important to reduce the recycling cost of the new development pattern. The main reason is that leading enterprises can drive the development of the upstream and downstream industrial chain, which is easy to form the "dandelion effect" and bring the "scale effect", which is condu-

${ }^{2}$ The data is from Anhui Provincial Bureau of statistics. 
cive to the reduction of the cycle cost of the new development pattern. In northern Anhui, there are obviously not many large-scale enterprises. Judging from the number of top 500 companies in the country in 2018, only 2 companies in the six cities of northern Anhui are on the list, and all of them are resource-based companies. No other manufacturing and service companies are on the list. In addition, from the $2018 \mathrm{~A}$-share In terms of the number of listed companies, there are 12 in Northern Anhui and 104 in Anhui Province, and the number of listed companies is obviously not many ${ }^{3}$.

\section{Realistic Basis}

In recent years, the digital economy has developed rapidly across the country, and the northern Anhui region is unwilling to lag behind. After years of vigorous investment, the northern Anhui region has gathered many development advantages in the construction of digital economy, laying a solid foundation for the higher quality development of the digital economy.

\subsection{The Main Body of Digital Economy Has Been Cultivated Well}

In recent years, a considerable amount of data has been accumulated in the field of digital economy in Northern Anhui Province. For example, Suzhou City has built the largest cloud computing industrial base in East China. Up to now, 2700 data cabinets are providing "basic cloud, application cloud, platform cloud" and other data services to more than 1000 enterprises; as of early June 2020, Fuyang Branch of Jianghuai big data center has collected data resources from 51 municipal departments and 6 counties, and published 1026 data resource directories, according to the total amount of 1.687 billion items, 2754 catalogues and 560 million data were shared with 16 units. $^{4}$.

\subsection{The Foundation of the Digital Industry Is Relatively Strong}

At present, the cities in northern Anhui have formed considerable industry advantages and characteristics in the digital industry fields such as information appliances, magnetic materials, display materials, and special cables. Taking Bengbu City as an example, it has gathered many 5G business-related companies, with an output value of over 6 billion yuan in 2019. There are also more than 1240 cloud computing big data and intelligent manufacturing related enterprises in the Suzhou City Cloud Computing Industry Base adjacent to Bengbu. In 2019, the base achieved a full-caliber output value of 20.3 billion yuan, an increase of $25 \%$, and fiscal revenue of 940 million yuan, and increase of $77 \%{ }^{5}$.

\subsection{Has a Wealth of Talents in the Digital Economy}

In recent years, North Anhui has held high-level talent matchmaking confe-

\footnotetext{
${ }^{3}$ The data is from Wind database.

${ }^{4}$ The data comes from China E-government website http://www.e-gov.org.cn/article-172867.html

${ }^{5}$ The data is from the website of Anhui Provincial Economic and information department http://jx.ah.gov.cn/sy/syzx/sxjxyw/index.html
} 
rences for years, attracting a large number of digital talents in the Internet, artificial intelligence, and big data to settle down. At the same time, some universities in northern Anhui have taken the lead in opening undergraduate majors in digital economy across the country. On the one hand, this will help attract more digital economy research talents, and on the other hand, it will also help cultivate a large number of digital economy talents.

\subsection{The Process of Industrial Upgrading Continues to Accelerate}

Taking the opportunity of supply-side structural reform in northern Anhui, combining digitalization and intelligence, a large number of smart factories have been built and a large number of digital workshops have been transformed. For example, Huaibei City has completed the intelligent upgrade and transformation of 95 enterprises in the past two years. The enterprises have purchased 193 robots, with an investment of more than 40 million yuan, and implemented more than 100 enterprises to "cloud"; Fuyang City, invested 20 billion yuan in technological transformation funds in 2019, Help companies build digital workshops and smart factories, and promote the intelligent and networked upgrade of traditional industries. In addition to the manufacturing industry, in the service industries of education, medical care, tourism, and retail in northern Anhui, as the level of digitalization continues to increase, industrial upgrading is also accelerating ${ }^{6}$.

\subsection{The Number of Digital Economy Formats Is Increasing}

In northern Anhui, on the basis of the ever-developing traditional application scenarios of the digital economy, some new business formats have been added. For example, during COVID-19 in Bozhou City, it was the first to try the live commerce of TCM, an online promotion event, sales exceeded 15 million yuan in two days, opening a new development model of "digital + TCM"; Suzhou City has built a digital financial service platform to expand financing channels for enterprises with a "digital + finance" model. Currently, 26 financial institutions have settled in ${ }^{7}$.

\section{Path Selection}

In summary, if the northern Anhui region wants to accelerate the formation of a new development pattern, the key depends on whether the difficulties and problems encountered in the construction of the new development pattern can be solved as soon as possible through the higher-quality development of the digital economy. In general, the implementation path of " 1235 " can be followed, that is, "1" center, "2" main line, "3" grand strategy and " 5 " acceleration. Specifically as follows:

\section{1. "1" Center}

A center is to center on the construction of a modern economic system. Con- 
structing a modern economic system is the focus and difficulty of economic work at this stage and for some time in the future, and it is also the ultimate goal. The new development stage has spawned a new development pattern, and the new development pattern needs the guidance of new development concepts. The ultimate goal of persisting in implementing the new development concept is to build a modern economic system, so the formation of a new development pattern will ultimately serve to build a modern economic system. Of course, the new development pattern and the modern economic system also have a dialectical and unified relationship. Through the construction of a modern economic system, it is also conducive to the transformation of development methods and development thinking, and is conducive to the accelerated formation of the new development pattern (Huang, 2020b). Therefore, the northern Anhui region must give full play to its late-comer advantages, take advantage of the huge advantages of the digital economy, and center on the construction of a modern economic system to lead the northern Anhui region to accelerate the formation of a new development pattern, and strive for the "Curved overtaking" of economic and social development.

\section{2. "2" Main Line}

To accelerate the formation of a new development pattern in northern Anhui, it is necessary to focus on the construction of a modern economic system. Based on this center, the focus should be on the two main lines of priority development of the digital industry and supply-side structural reforms.

1) Priority development of the digital industry. To accelerate the formation of a new development pattern in northern Anhui with the high-quality development of the digital economy, the development of the digital industry must first be emphasized. At the same time, the digital foundation of the northern Anhui also needs to be further strengthened. The development process should give priority to the development of the digital economy. By leading the priority development of the digital industry, it will help the northern Anhui region to accelerate the formation of a new development pattern.

2) Structural reforms on the supply side. Supply-side structural reform is not only one of the key tasks of China's current economic reform, but also a key reform to form a new development pattern (Feng, 2020; Dong, 2020). The new development pattern is a spiral-rising cycle, a cycle of rising consumption levels, which requires reforms from the supply side. The northern Anhui region should also combine its own characteristics, use big data to mine consumer demand, accurately connect, and personalize production, accelerate the supply-side structural reform of the northern Anhui region, and accelerate the formation of a new development pattern.

\section{3. "3" Grand Strategy}

Based on the two main lines of priority development of the digital industry and 
supply-side structural reforms, northern Anhui can be guided by Innovation-Driven strategies, "Double Leading Enterprise" strategies and Rural Revitalization strategies, and continue to advance the pace of building a new development pattern.

1) Innovation-Driven strategy. Innovation is the first driving force for the construction of a new development pattern (Pu \& Yang, 2020). Northern Anhui must be guided by innovation, give full play to its own advantages, and increase $\mathrm{R} \& \mathrm{D}$ investment. On the one hand, it is committed to tackling the difficulties of cycle at the national level, such as special glass, clean energy, smart agriculture, etc.; on the other hand, it increases the innovation of the digital economy. Through continuous innovation in the digital economy, while assisting the rapid formation of a new development pattern in northern Anhui, it also contributes to the formation of a new development pattern at the national level.

2) "Double Leading Enterprise" strategies. "DLE" strategy is the digital enterprise leader strategy and leading enterprise digitization strategy. In northern Anhui, on the one hand, we must increase investment and optimize the direction of investment, and focus more on large digital companies or large leading companies; on the other hand, we must actively cultivate existing large companies and help existing large digital companies develop into digital leading companies. Help existing leading companies to develop digitally. Through the driving effect of leading enterprises, it will attract upstream and downstream enterprises, accelerate industrial agglomeration, form a scale effect, and promote the formation of a new development pattern in northern Anhui as soon as possible.

3) Rural Revitalization strategy. The Rural Revitalization strategy is conducive to accelerating rural development and increasing farmers' income. The vast rural areas are one of the key areas for smooth domestic circulation. The northern part of Anhui must actively promote the construction of "digital + rural areas", and strive to realize e-commerce service "village-to-village"; it is necessary to further promote the construction of "digital + agriculture", improve the level of agricultural science and technology, and improve the efficiency of agricultural operations. Through the digital economy to empower Rural Revitalization strategies, increase the disposable income of farmers, let the vast rural population join the ranks of consumption upgrades, and contribute to the rapid formation of a new development pattern.

\section{4. "5" Acceleration}

Under the guidance of the "Three Strategies", to accelerate the formation of a new development pattern through the high-quality development of the digital economy, northern Anhui also needs to accelerate the progress in the following five aspects.

1) Accelerate the accumulation of digital talents. The accumulation of digital talents in northern Anhui can go further on the existing basis. On the one hand, it encourages universities in northern Anhui to increase the allocation of digital 
economy-related majors and accelerate the cultivation of talents in digital economy management, technology, and law. On the other hand, the introduction of digital talents still needs to be continuously strengthened to provide solid conditions for digital talents, and strive to allow digital talents to establish a mentality of "entering northern Anhui and not wanting to leave".

2) Accelerate the development of digital finance. The northern Anhui region must make more efforts in the development of the financial industry, especially to accelerate the development of digital finance. For example, through in-depth cooperation between the government, banks and enterprises, accelerate the establishment of digital financial platforms, strengthen the construction of industrial funds, venture capital funds, angel funds and other funds, and focus more on digital economic projects in investment projects; at the same time, strengthen cooperation with other For cooperation between existing funds in the region, the government must be brave to provide guarantees for high-quality projects, and to finance capital channels for the development of digital industrialization and industrial digitalization.

3) Accelerate high-level opening to the "outside". The term "outside" here has two meanings, one refers to foreign countries, and the other refers to other areas in the country outside of Northern Anhui. On the one hand, the northern Anhui region should make great efforts to improve the business environment, with the construction of a "digital government" as the starting point, standardize the process, make matters transparent, accelerate the construction of a service-oriented government, and provide the greatest support for domestic and foreign enterprises to invest in northern Anhui, and let them come with peace of mind, come with comfort, and come with confidence; on the other hand, rely on the Anhui Free Trade Zone (Bengbu) area to accelerate the opening process and digitalization process of new materials, new energy and other industries, and lead technological innovation and open development in northern Anhui.

4) Accelerate the upgrading of the value chain and the industrial chain. To accelerate the formation of a new development pattern in northern Anhui, it is necessary to solve the shortcomings of the industrial chain and value chain as soon as possible, to accelerate the promotion of the industrial chain and value chain to the mid-to-high end, and to make full use of the digital economy to solve this acceleration energy problem. The digital economy can empower enterprises in the middle and low end of the industrial chain and value chain, accelerate the digital transformation process of these enterprises, promote the transformation and upgrading of enterprises, and give them the ability to enter the middle and high end of the industrial chain and value chain, and ultimately improve position in the industrial chain and value chain, and then attract more upstream and downstream enterprises in the chain to invest in northern Anhui. Through the in-depth integration and development of the digital economy and industries, it will accelerate the formation of a new development pattern in northern Anhui. 
5) Speed up the process of regional mutual aid and sharing. The six cities in northern Anhui should work together and meet each other halfway. They should only seize this new opportunity and strive for greater achievements. For example, in the development of digital finance, the six municipal governments in northern Anhui can work together to establish the North Anhui Revitalization Development Cooperation Fund and the Digital Industry Development Cooperation Fund, etc., to provide joint support for high-tech enterprises, key industries, and key areas in the northern Anhui; In the development of the digital economy, cooperation must be strengthened, digital information must be jointly constructed and shared, and vicious competition must be avoided. The construction of the digital economy must form a harmonious situation that not only goes hand in hand but also reflects characteristics. The six cities in northern Anhui will achieve higher-quality development of the digital economy through mutual aid and sharing, and promote the rapid formation of a new development pattern.

\section{Conclusion}

To sum up, Northern Anhui has the realistic foundation of higher quality development of digital economy, and it is feasible to accelerate the formation of the new development pattern in Northern Anhui through higher quality development of digital economy. However, to solve the difficulties and problems encountered in the construction of the new development pattern as soon as possible, it is necessary to fully demonstrate the great charm of the digital economy, fully develop its leading role, and promote the continuous improvement of the cycle efficiency of the new development pattern, the continuous improvement of the cycle quality, and the cycle cost continues to decrease. If the northern Anhui region can follow the above-mentioned "1235" path well, we believe that the northern Anhui region will be able to take the lead in the construction of the new development pattern, and it will definitely be able to truly realize the "revitalization of the northern Anhui".

\section{Fund Project}

Anhui Philosophy and Social Science Planning Project (Key Project) "Research on Performance Evaluation and Realization Path of High-quality Economic Development in Northern Anhui under the New Development Concept" (AHSKZ2018D05).

\section{Conflicts of Interest}

The authors declare no conflicts of interest regarding the publication of this paper.

\section{References}

Bi, J. Y., Zhang, Z. R., \& Yuan, Q. (2019). Do a Great Article on Promoting Reform 
Through Opening Up. Modern Enterprise, 2, 8-9.

Dong, Y. (2020). Coping with New Challenges, Building a New Pattern and Generating New Driving Forces. Economy, 10, 48-50.

Fan, Y. X., \& Xu, H. (2020). Financial Support for High-Quality Development of Digital Economy: Core Mechanism and Experience Enlightenment. Reform, No. 8, 83-91.

Feng, Q. B. (2020). Accelerate the Formation of a New Pattern of Economic Development. Red Flag Manuscript, 18, 28-30+1.

Huang, Q. H. (2020a). A “Dual Circulation” Development Pattern: Profound Connotation, the Background and Suggestions. Journal of Beijing University of Technology (Social Sciences Edition), 1-7. http://kns.cnki.net/kcms/detail/11.4558.G.20200917.1255.002.html

Huang, Q. H. (2020b). New Development Pattern of "Double Cycle" the Important Target and Focus of China's Economic Policy in the Future. Money China, 28, 11-12.

Jiang, X. J. (2020). Digital Economy Will Become an Important Force to Promote Double Circulation. https://baijiahao.baidu.com/s?id=1678540035429423111\&wfr=spider\&for $=$ pc

Li, Y. Y., Zhu, X. L., \&Sun, L. J. (2020). Research on High Quality Development of Digital Economy in China Based on American Experience. Journal of Commercial Economics, 15, 189-192.

Li, Z. G. (2020). Breaking through the "Blocking Point" in the Economic Cycle with System Innovation. Governance, 31, 20-24.

Liu, Y. (2020). Digital Economy Steadily Promotes the Promotion of the New Development Pattern. Economy, 10, 53-55.

Lu, M. F. (2020). Construction of the New Development Pattern: Concept, Characteristics, Development Difficulties and Realization Path of Economic Internal Circulation. Journal of Xinjiang Normal University (Edition of Philosophy and Social Sciences), No. 4, 1-13.

Lv, X., \& Li, Y. (2020). Coordinate Development and Security to Promote High Quality Development of Digital Economy. China Information Security, No. 5, 71-73.

Pu, Q. P., \& Yang, C. L. (2020). Realistic Logic, Implementation Path and Era Value of Constructing the New Development Pattern of "Double Cycles". Journal of Chongqing University (Social Science Edition), 1-11. http://kns.cnki.net/kcms/detail/50.1023.C.20200817.1402.002.html

Qian, X. F., \& Pei, T. (2020). The New Development Pattern of Domestic and International Dual Cycle: Theoretical Logic and Endogenous. Journal of Chongqing University (Social Science Edition), 1-13. http://kns.cnki.net/kcms/detail/50.1023.C.20200915.1512.002.html

Ren, Z. A., \& Xing, H. (2020). The Construction Difficulties and Breakthrough Strategies of Modern Economic System in Northern Anhui. Journal of Anhui University of Science and Technology (Social Science), 2, 13-22.

Shi, Z. J., \& Shan, Y. (2020). Understanding the Data Element Market and Promoting the High Quality Development of Digital Economy. China Internet, 6, 38-39.

$\mathrm{Xu}$, Q. Y. (2020). New Development Pattern of Dual Circulation: How to Understand and Build. Finance Forum, 9, 3-9. 